\title{
A Study on the Effect of Exercise and Fitness on the Well-being of the Elderly
}

\author{
Tian-lin CHEN* \\ Psychological Counseling Center \\ Jiangxi University of Traditional Chinese Medicine \\ Nanchang, Jiangxi, China
}

\author{
Xia-chao XIE \\ Graduate School \\ Jiangxi University of Traditional Chinese Medicine \\ Nanchang, Jiangxi, China
}

\author{
Yong-fei CHEN \\ School of Computer Science \\ Jiangxi University of Traditional Chinese Medicine \\ Nanchang, Jiangxi, China
}

\begin{abstract}
To investigate the effects of exercise and fitness on the four types of well-being (subjective well-being, psychological well-being, social well-being, and realization of well-being) of the elderly. Methods adopt the "Well-being Questionnaire" to select the elderly in Nanchang City as the research objects. 50 old people from the exercise and fitness group and the lack of exercise group were selected respectively by stratified random sampling. Results show that the subjective well-being score of the exercise and fitness group was $4.79 \pm 1.13$, the psychological well-being score was $5.02 \pm 1.24$, the social well-being score was $5.27 \pm 1.29$, and the realization of well-being score was $3.37 \pm 0.92$. The exercise and fitness group was higher than those in the lack of exercise group $(\mathbf{p}<0.01)$ in subjective well-being, psychological well-being, and social well-being, and there was no statistically significant difference in the realization of well-being. The conclusion is that exercise fitness has a positive effect on the subjective well-being, psychological well-being and social well-being of the elderly, and the impact on the realization of well-being is not significant.
\end{abstract}

Keywords-well-being; seniors; exercise and fitness; lack of exercise

\section{INTRODUCTION}

According to the 2018 data released by the National Bureau of Statistics, China's population aged 60 and over is 249.49 million, accounting for $17.3 \%$ of the country's total population. This shows that China has entered an aging age.

As an important research field in the study of positive psychology, well-being can effectively reflect the individual's social fitness status and is an important comprehensive psychological indicator to measure the quality of life of individuals[1]. Therefore, how to find a simple and effective way to improve the well-being of the elderly is a problem that many studies are concerned about. Exercise psychology research shows that exercise as a very economical health behavior has good physical and mental health effects on individuals, and is also the most basic and effective way to improve the health status and quality of life of the elderly[2].

In recent years, there have been many studies on the effects

Project supported by the subject of 2017 national innovation and entrepreneurship training program for college students (NO.201710412001) Corresponding author: Tian-lin CHEN of various types of exercise and fitness on the well-being of the elderly. However, most of these studies are mainly focused on the study of subjective well-being, less on other kinds of well-being, and they are all a single study of well-being, which cannot reflect comprehensive connotation of the well-being of individuals[3]. Based on this, this study combines the four senses of well-being, such as subjective well-being, psychological well-being, social well-being, and realization of well-being, to explore the impact of exercise and fitness on the well-being of the elderly. It is far more comprehensive and meticulous than study a single kind of well-being.

\section{OBJECTS AND METHODS}

\section{A. Objects}

In the three communities of Nanchang City, retirees were selected as research subjects. The subjects were divided into two groups, 50 in exercise and fitness group, 25 men and women respectively, with an average age of $(67.7 \pm 7.6)$ years, 50 insufficient exercise group, 25 men and women respectively, with an average age of $(68.1 \pm 5.9)$ years. The exercise and fitness group is defined as exercising 5 times or more per week in the past year. Each exercise time is more than 30 minutes; the insufficient exercise group is defined as exercise $\leq 1$ times per week in the past year, and each exercise time is less than 10 minutes. There was no significant difference in age between the exercise and fitness group and the insufficient exercise group ( $\mathrm{p}>0.05)$

\section{B. Methods}

The research tools used in this study are the four questionnaires of Subjective Well-being Questionnaire, Psychological Well-being Questionnaire, Social Well-being Questionnaire, and Realization of Well-being Questionnaire. The 7-level scoring method is used. The lowest score is 1 point and the highest score is 7 points. Divided into 4 points, at 4 points or so, the level of well-being is at an intermediate level, much higher than 4 points, indicating that the level of well-being is higher, far below 4 points, indicating a low level of well-being. The Subjective Well-being Questionnaire and the Psychological Well-being Questionnaire are derived from 
the Comprehensive Well-being Questionnaire prepared by Yuan-jiang MIAO[4] in his doctoral thesis in 2003. The Social Well-being Questionnaire was written by Qing-hua WANG[5] in 2009. The scale for measuring social well-being compiled in the master's thesis, the Realization of Well-being Questionnaire was revised by Ya-lin HU[6] in the 2011 master's thesis based on the Realization of Well-being Questionnaire compiled by Waterman et al. The above scales are reliable, efficient and widely used, and can be used as a stable and reliable research measurement tool.

\section{RESULTS}

A. The overall situation of the well-being of the elderly in the exercise and fitness group

In this survey, the subjective well-being scores of the exercise and fitness group were $4.79 \pm 1.13$, the psychological well-being score was $5.02 \pm 1.24$, the social well-being score was $5.27 \pm 1.29$, and the realization of well-being score was 3.37 \pm . 0.92, in addition to a low level of realization of well-being, other well-being is not much different, basically at the upper-middle level. The scores of well-being in older men and women in the healthy exercise group were similar to those in the overall situation. Except for a moderately low level of realization of well-being, other well-being levels were above average.

\section{B. The situation of four types of well-being in the elderly in} the exercise and fitness group

To further verify whether subjective well-being, psychological well-being, social well-being and realization of well-being can explain the well-being of the elderly from different aspects, this study analyzes the four types of the well-being of the elderly in the exercise group. From the perspective of psychological measurement, if the correlation coefficient between related variables is too high, it means that the degree of coincidence between the variables is higher and the lower the correlation coefficient, the more obvious the difference between the variables. The results of this study show that (TABLE I), the principal correlation coefficient between subjective well-being, psychological well-being, social well-being, and realization of well-being is between 0.301 and 0.396, so it can be considered that these four types of well-being are four different forms. The sense of well-being can interpret the different contents of the well-being of the elderly in exercise and fitness from different levels, and cannot substitute each other.

TABLE I. THE CORRELATION COEFFICIENT OF FOUR TYPES OF WELL-BEING AMONG THE ELDERLY IN THE FITNESS GROUP (R)

\begin{tabular}{|c|c|c|c|c|}
\hline & $\begin{array}{l}\text { Subjective } \\
\text { well-being }\end{array}$ & $\begin{array}{l}\text { Psychological } \\
\text { well-being }\end{array}$ & $\begin{array}{c}\text { Social } \\
\text { well-being }\end{array}$ & $\begin{array}{c}\text { Realization } \\
\text { of } \\
\text { well-being }\end{array}$ \\
\hline $\begin{array}{l}\text { Subjective } \\
\text { well-being } \\
\end{array}$ & 1 & & & \\
\hline $\begin{array}{c}\text { Psychological } \\
\text { well-being }\end{array}$ & $0.312 * *$ & 1 & & \\
\hline $\begin{array}{c}\text { Social } \\
\text { well-being }\end{array}$ & $0.329 * *$ & $0.396 * *$ & 1 & \\
\hline $\begin{array}{l}\text { Realization of } \\
\text { well-being }\end{array}$ & $0.301 * *$ & $0.342 * *$ & $0.318 * *$ & 1 \\
\hline
\end{tabular}

Note: ${ }^{* *} \mathrm{p}<0.01,{ }^{*} \mathrm{p}<0.05$, the same below

\section{Differences in well-being between the exercise and fitness group and the insufficient exercise group}

In the survey, the well-being of the elderly in the exercise and fitness group and the elderly in the lack of exercise group were compared (see TABLE II). The former is higher than the latter in terms of subjective well-being, psychological well-being and social well-being. There was no statistically significant difference between the two in the realization of well-being.

TABLE II. COMPARISON OF WELL-BEING BETWEEN EXERCISE AND FITNESS GROUP AND INSUFFICIENT EXERCISE GROUP (M \pm SD)

\begin{tabular}{|c|c|c|c|}
\hline & $\begin{array}{c}\text { exercise and fitness } \\
\text { group }\end{array}$ & $\begin{array}{c}\text { lack of exercise } \\
\text { group }\end{array}$ & $\mathrm{t}$ \\
\hline $\begin{array}{c}\text { Subjective } \\
\text { well-being }\end{array}$ & $4.79 \pm 1.13$ & $3.82 \pm 1.06$ & $2.36^{* *}$ \\
\hline $\begin{array}{c}\text { Psychological } \\
\text { well-being }\end{array}$ & $5.02 \pm 1.24$ & $3.79 \pm 1.16$ & $2.74^{* *}$ \\
\hline Social well-being & $5.27 \pm 1.29$ & $3.87 \pm 0.98$ & $2.81^{* *}$ \\
\hline $\begin{array}{c}\text { Realization of } \\
\text { well-being }\end{array}$ & $3.37 \pm 0.92$ & $3.35 \pm 0.96$ & 1.32 \\
\hline
\end{tabular}

D. Gender differences in the well-being of the elderly in the exercise and fitness group

In order to understand whether there is a difference in the well-being between old men and women in healthy exercise, it is found (TABLE III) that in terms of subjective well-being, old men in the exercise and fitness group are higher than old women; in psychological well-being and social well-being, the old men in the exercise and fitness group are lower than the old women; and the difference between the two is not significant in the realization of well-being.

TABLE III. COMPARISON OF THE SEX OF THE ELDERLY IN THE EXERCISE AND FITNESS GROUP $(\mathrm{M} \pm \mathrm{SD})$

\begin{tabular}{|c|c|r|c|}
\hline & \multicolumn{1}{|c|}{ Old men } & \multicolumn{1}{c|}{ Old women } & $\mathrm{t}$ \\
\hline Subjective well-being & $4.99 \pm 1.12$ & $4.48 \pm 1.09$ & $1.97^{*}$ \\
\hline Psychological well-being & $4.58 \pm 1.15$ & $5.21 \pm 1.27$ & $-2.01^{*}$ \\
\hline Social well-being & $4.77 \pm 1.09$ & $5.37 \pm 1.18$ & $-1.99^{*}$ \\
\hline Realization of well-being & $3.45 \pm 0.97$ & $3.31 \pm 0.92$ & 0.62 \\
\hline
\end{tabular}

\section{DISCUSSION}

From the perspective of concept definition, subjective well-being, psychological well-being, social well-being and the realization of the well-being of the four types of well-being described levels, angles, content are different. This study abandons the way in which individuals are described by well-being with a single sense of well-being, and combines the four senses of well-being, such as subjective well-being, psychological well-being, social well-being, and realization of well-being, to describe the well-being of the elderly. This is a new idea. The results of the study found that the correlation coefficient between these four types of well-being in the exercise and fitness group is between 0.301 and 0.396 , which indicates that these four types of well-being have different characteristics and can explain the different contents of the exercise and fitness old people from different levels. They cannot be replaced by each other. This further supports the idea of using four types of well-being to describe the well-being of the elderly in this study. 
At the same time, the survey also showed that the subjective well-being, psychological well-being and social well-being of the elderly in the exercise and fitness group were at the upper-middle level. At the same time, the elderly in the exercise and fitness group had higher subjective well-being, psychological well-being and social well-being than the lack of exercise group, which is consistent with some existing research results. Studies such as Lei ZHU[7] and others have shown that the subjective well-being of the elderly participating in physical fitness is at a medium-high level.

The results of this study show that the elderly in the exercise and fitness group and the lack of exercise group are not significantly different in terms of realization of well-being. The former is higher than the latter in terms of subjective well-being, psychological well-being and social well-being, which is consistent with the results of previous studies. Jie WANG[8] and others in the various communities in Ji'an City by stratified random sampling method to extract retirees conducted research results also showed that the exercise group well-being is higher than the insufficient exercise group.

The exercise and fitness group is higher in subjective well-being than the lack of exercise group for exercise and fitness can alleviate the negative emotional experience and bring more positive emotional experience, thus enhancing the individual's subjective well-being. The psychological well-being of the elderly in the exercise and fitness group is higher than that in the insufficient exercise group for healthy exercise can bring about better health and vitality feelings. At the same time, this feeling will promote the self-identification of the elderly, and it is not easy to feel old, so the psychological well-being of the exercise and fitness group is higher. In terms of social well-being, the elderly in the exercise and fitness group is higher than the insufficient exercise group for exercise and fitness are beneficial to create a warm interpersonal relationship, thus stimulating the individual's social identity, so the social well-being of the exercise and fitness group is higher. In terms of realization of well-being, this study shows that whether the elderly in the exercise and fitness group or the elderly with insufficient exercise group, the level of well-being is moderately low, and the difference between the two groups is not significant, which indicates that exercise and fitness will bring many benefits to the body and mind, but for the elderly in China, retirement means withdrawing from their own career, including playing with the grandchildren and enjoying their old age, so the pursuit of self-realization will be weakened. Therefore, the realization of well-being in the entire elderly group is at the lower middle level.

The study also found that there are differences in well-being between old men and old women in the exercise and fitness group. In fact, many studies have confirmed that the subjective well-being of Chinese old women is higher than that of old men. For example, Wei-jian ZHANG[9] found that the old female residents have higher subjective well-being than the old male residents in his Research on the influencing factors of subjective well-being of elderly residents in China. However, the results of this study show that in terms of subjective well-being, the old men in the exercise and fitness group are higher than the old women, which is contrary to the results of the subjective well-being of old women in real life than men. The only explanation is that exercise and fitness are more effective in enhancing the positive emotions of the old men, so the improving level of subjective well-being is also greater than that of old women. In terms of psychological well-being and social well-being, the old men in the exercise and fitness group are lower than the old women. This may be that old women prefer to communicate with each other in exercise and fitness than old men, so as to obtain a warmer and more harmonious interpersonal relationship, and to feel the sense of identity and belonging in the community.

\section{CONCLUSION}

In short, with the increase of age, aging not only degrades the individual's physiological function, but also leads to the reduction of physical activity, and also brings the negative psychological state such as sensation and loss to the individual, while increases the social activities such as exercise and fitness can not only ensure that the elderly body is in a healthy state, prolong the aging process time, but also have a positive effect on the subjective well-being, psychological well-being and social well-being of the elderly,

\section{REFERENCES}

[1] Hui-min DA. The Study of Subjective Well-being of the Elderly in China for 10 years: Review and Prospects [J]. Chinese Journal of Gerontology, 2019, 39 (09): 2288-2294. (In Chinese)

[2] Liu-juan HAI. Research on the Relationship between College Students' Fitness, Mental Resilience and Well-being [D]. Nanchang University, 2012. (In Chinese)

[3] Xu ZHANG. Research on the Well-being of College Counselors in Jiangxi Province [D]. Nanchang University, 2012. (In Chinese)

[4] Yuan-jiang MIAO. Well-being in the Perspective of Psychology [D]. Nanjing Normal University. 2003. (In Chinese)

[5] Qing-hua WANG. Research on the Social Well-being of College Students [D]. Nanchang University. 2009. (In Chinese)

[6] Ya-lin HU. Research on the Psychological Structure of College Students and Graduate Students to Achieve Well-being [D]. Nanchang University. 2011. (In Chinese)

[7] Lei ZHU. Study on the Impact of Different Fitness Methods on Subjective Well-being of the Elderly [D]. Yangtze University, 2015. (In Chinese)

[8] Jie WANG. The Impact of Physical Exercise on the Well-being of the Elderly [J]. Chinese Journal of Gerontology, 2011, 31 (23): 4644-4645. (In Chinese)

[9] Jian-wei ZHANG. Research on the Influencing Factors of Subjective Well-being of Elderly Residents in China [D]. Shandong University, 2014.(In Chinese) 